tific institution of the national capitol, founded expressly for the dissemination of useful knowledge, and be directly in line with their publication in past years, of the indexes to the literature of specific chemical bodies, which has so much redounded to their credit? It seems to me at least that it would be a work worthy of their best endeavor, and of whose great utility there could be no question whatever.

\title{
CAUSE OF THE LOSS IN WEIGHT OF COMMERCIAL PLAT- INUM, WHEN HEATED UNDER SOME CONDITIONS.
}

\author{
BY ROEBRT W. HALL. \\ kecsivel itut 15. 150 .
}

$T^{H}$

$\mathrm{HE}$ fact that commercial platinum sometimes loses weight when heated has been frequently noticed and experiments made to determine the cause of the loss. This loss has been observed under at least seren conditions.

I. When platinum is made the cathode for the spark from an induction coil.-That platinum is dissipated under this condition, was observed by Plicker ${ }^{1}$ and very fully described by him. A. W. Wright and others studied the same phenomena. The platinum is dissipated alike in air, in vacuum, and in hydrogen, and the phenomena are regarded as purely physical or mechanical.

2. When platinum is heated in a Bunsen gas flame, sufficiently, reducing to deposit some carbonaceous matter on the platinum.Rémont ${ }^{3}$ obtained in this way, in thirty minutes, a deposit weighing 22 milligrams and containing ro milligrams of platinum. Rémont made some experiments to show that this loss is not due to the heated carbonaceous matter alone. $\mathrm{He}$ attributed it to some constituent of the gas.

3. When platinum is heatcd in the ordinary smokeless Bunsen fame.-Some observers note a constant loss under these conditions. Wittstein ${ }^{4}$ found such a loss and attributes it to osmium, which he found in the platinum scrap of that time. Stolba ${ }^{5}$ found that a platinum crucible lost weight at the rate of I6 milligrams in twelve hoturs. Stolba remarks that while he

\footnotetext{
1. Ann. Phys. Chem., ro3, go (1855)

2 Sill.J. Sci. and Arts, Jamuary, $157 \%$

s Bull. Soc. Chim., 35, 486 (1851).

4 Dingler's poly. J., 179, 299 (1866).

5 lbid., 198, I77 (1870).
} 
does not deny the possible presence of osmium, there would have to be more osmium in the platinum than in the original ore, to account for the continuous losses he observed. Erdmann, with Pettenkofer, had, however, studied the behavior of platinum crucibles in the Bunsen flame and observed the formation of a gray coating, but without loss or gain in weight. Erdmann concludes that the gray coating is due to molecular change in the platinum. Crookes ${ }^{2}$ discusses Erdmann's paper and agrees with him.

The writer's experience agrees with that of Erdmann, so far as constancy of weight is concerned. Possibly some of the platinum of commerce about 1866 to 1870 differed in composition from that commonly used. It may be noted here that platinum heated in a flame of hydrogen containing arsine and then strongly ignited, shows the phenomena observed by Erdmann in a very marked degree.

4. When platinum is very strongly heated in a furnace for firing porcelain.-Elsner found that platinum burned into porcelain, was entirely dissipated when exposed to the full heat of an oven used for firing porcelain, during the burning of a batch.

Platinum black, however, placed in a small porcelain crucible, under the same conditions, only melted to small globules, with a metallic luster.

5. When platinum is heated in a combustion tube in air. $-\mathrm{H}$. Kayser ${ }^{*}$ attempted to free air from possible hydrocarbons by passing it over platinum in a glass tube heated externally. $\mathrm{He}$ observed phenomena, which he explained by the assumption that the platinum gave up finely divided particles to the air.

6. When platinum is heated by an electric current. - That platinum is dissipated when heated in air by the electric current seems to have been discovered first by Thomas A. Edison. ${ }^{s}$

Edison observed that glass, surrounding the wire, became covered with a mirror of what he assumed to be metallic platinum and that when the wire was placed in a bulb and as

1 J.prakt. Chem., 79, II7 (I860).

2 "Select Methods in Chemical Analysis," 2nd Ed., p. 68 r.

"J.prakt. Chem., 99, 257 (1866), from Chem. tech. Mitth. (Elsner) 7, 36 (1857-1858).

4 Ann. Phys. Chem., 34 (1888).

5 Chem. Nezus, 40. 152. from Proc. Am. Ass., 1879, 173. 
perfect a vacuum as possible produced, the loss ceased. Edison pronounced the action to be purely uechanical.

Nahrwold, ${ }^{1}$ in apparent ignorance of Edison's work, repeated part of Edison's experimetsts and further observed that the metallic coating dissolved in aqua regia, only in part. Nahrwold pronounces no opinion as to the nature of the action.

Berliner ${ }^{2}$ endeavored to explain the action. He found that platinum, which had been exposed to air, gave up gas when heated in a vacuum, that while doing so platinum was dissipated, giving a deposit on glass cylinders surrounding the metal and that the dissipation of the platinum ceased, when gas was no longer given off. In hydrogen the behavior was exactly the same as shown by a single successful experiment and Berliner, therefore, concluded that the action was a purely mechanical one caused by the escaping gases.

7. When platinum is heated before the blast-lamp.-Beilstein notes that platinum crucibles, both of pure and of less pure platinum, lost weight to an important degree on ignition but that after repeated ignition the loss became less. The writer's experience does not agree with this. For example, in a series of experiments, a crucible which had been used for some years, was ignited nineteen times, under varying conditions, with a total loss of 10.3 milligrams; on being ignited for the twentieth time (see Table B, Experiment I) it showed a loss of 2 milligrams in thirty minutes, - a greater loss than was observed in any of the preceding experiments. Perhaps if a new crucible had been used for the first experiment of the series, results like Beilstein's, would have been obtained.

The attention of the writer was directed to the subject soon after moving to a new laboratory, by finding that the ordinary platinum crucibles of commerce lost weight so rapidly, when used for the conversion of calcium oxalate into calciun oxide, that even an approximately constant weight could not be reached.

This was the more remarkable, as the burners and general arrangements were the same, as had been used for several years,

1 Ann. Phys. Chem. 31.467 (188-).

2 Lbia., 33. $2 \mathrm{~s}_{\mathrm{T}}$ (1885).

"short abstract Chem. Centrbl., 1580,614. Origizal in $\boldsymbol{Z}$, rusk, chim, obse, 12, 1850, not accessible. 
with the exception that for a foot-blower, there was substituted a steady blast from a blowing engine, giving a more evenly high temperature.

The gas used was a mixture of retort gas and of the so-called "water-gas" enriched with naphtha gas. It contained about I 5 per cent. of carbon monoxide and in this respect resembled the gas, which had been used formerly, without causing any loss of weight in the crucibles.

The loss was not due to the high temperature alone, for the writer has frequently heated crucibles with a steady blast, to the most brilliant "blue whiteness," without loss.

Experiments showed that the loss was not due to dust in the air or gas, acting as a sand-blast, for filtration of the air and gas through cotton-wool made no difference; nor to unusual amounts of the impurities removable by alkalies in the gas, for the losses still continued after a careful purification of the gas by passing it through potassium hydroxide solution and over "soda-lime."

Nor was the loss likely to be due to any peculiarity in the platinum used, for old and new crucibles of soft, comparatively pure platinum and a crucible of a platinum-iridium alloy, gave about the same results. In every case, after heating, the platinum showed a somewhat roughened surface, with a most beautiful silvery luster.

TABLE A.

Soft, commercial "pure" platinum from Eimer and Amend, New York.

\begin{tabular}{|c|c|c|c|c|c|c|c|}
\hline No. & 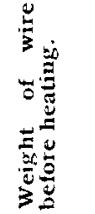 & 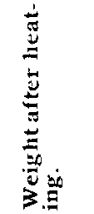 & Gas used. & 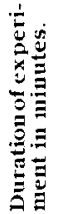 & 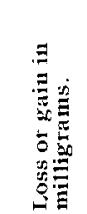 & 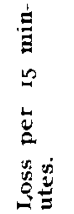 & Remarks. \\
\hline I. & 2.9085 & 2.9085 & $\mathrm{CO}$ & 30 & 0.0 & 0.00 & \\
\hline 2. & 2.9085 & 2.9085 & " & 30 & 0.0 & 0.00 & \\
\hline 3. & 2.9083 & 2.9080 & "6 & 35 & -0.3 & 0.13 & $\left\{\begin{array}{l}\text { Supply of gas insuffi- } \\
\text { cient. Some air may } \\
\text { have gained access. }\end{array}\right.$ \\
\hline 4. & 2.9080 & 2.9054 & air & 30 & -2.6 & 1.30 & $\begin{array}{l}\text { Slight mirtor on the } \\
\text { glass. }\end{array}$ \\
\hline 5. & 2.9054 & 2.9022 & " & 30 & -3.2 & 1.60 & $\begin{array}{l}\text { Slight mirror on the } \\
\text { glass. }\end{array}$ \\
\hline 6. & 2.9022 & 2.8977 & " & 45 & -4.5 & 1.50 & $\begin{array}{l}\text { Slight mirror on the } \\
\text { glass. }\end{array}$ \\
\hline
\end{tabular}




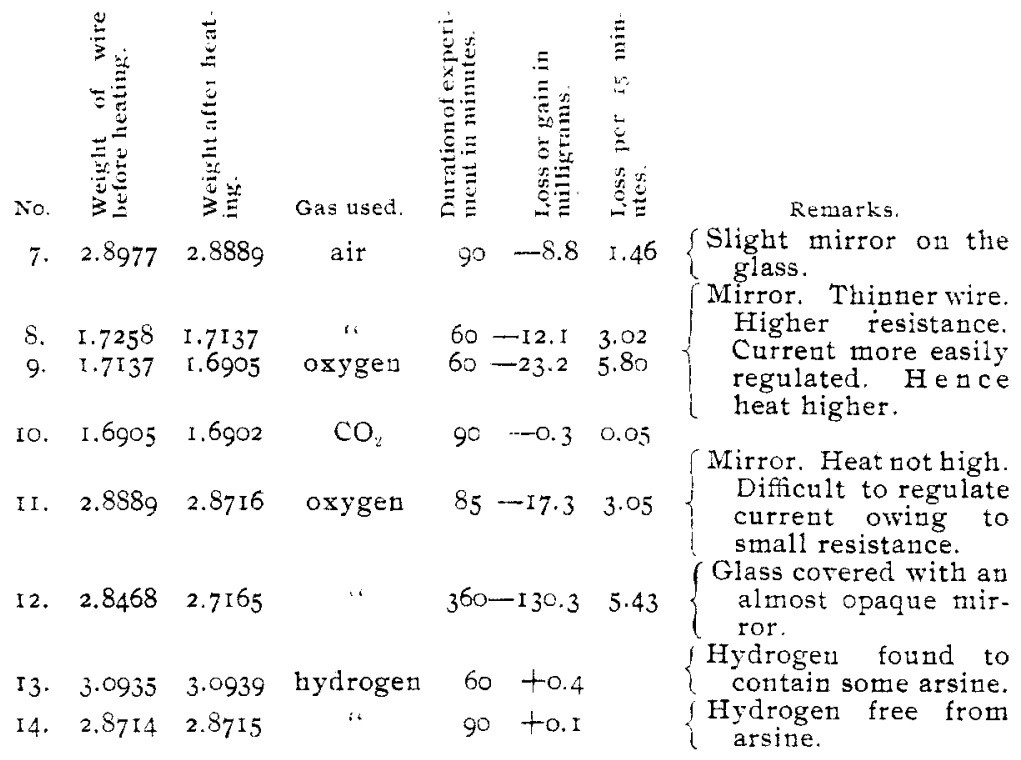

Some experiments were therefore undertaken to answer the question why platinum crucibles sometimes keep a constant weight, when heated in a gas flame, to a temperature very near their melting-point and why they sometimes lose weight, at a rate amounting to a milligram in fifteen minutes.

Wires of the ordinary soft "pure" platinum of commerce, about $40 \mathrm{~cm}$. in length, were placed within a glass tube $78 \mathrm{~cm}$. in length and $3.5 \mathrm{~cm}$. in diameter, closed at each end with caoutchouc stoppers and provided with openings for the introduction and exit of the different gases used.

The platinum wires used were hung on platinum rods and these again hung on copper conducting wires. A stream of the gas used was passed through the apparatus and then the wire was brought to a temperature as near its melting-point as could be done safely, by means of an electric current.

The details of these experiments are given in table A.

The results of these experiments was unexpected.

They show that the loss of weight, in the reducing or neutral gases, carbon monoxide or carbon dioxide, is zero or very slight; that in hydrogen there is a very slight gain, while 
in air and oxygen the loss is very rapid, in Experiment No. I2, amounting to 5.4 milligrams in each fifteen minutes. The two experiments with hydrogen, showing an actual gain, are not necessarily in conflict with Berliner's result, since in these two experiments the platinum was cooled in hydrogen, while in Berliner's experiment the platinum was cooled in a vacuum. The following experiments were made, however, and do seem to conflict with Berliner's result. The wires used in Experiments $I_{3}$ and $I_{4}$, were heated by the current, for sixty and ninety minutes, respectively, in an atmosphere of carbon dioxide. After this treatment they weighed within 0.05 milligram of the original weights; that is, the differences were within the error of weighing. It may be remarked that Berliner's experiments were qualitative, but he describes the deposit from hydrogen as an "opaque platinum mirror." Berliner's experiments were beautifully planned and no explanation of the apparent conflict suggests itself.

It, therefore, appeared probable from the result of these experiments, that a highly oxidizing gas flame would cause a greater loss of platinum, than a more reducing one.

Experiments were made to test this by placing a platinum crucible in a blast-flame, first high up in the flame, above the point where the maximum temperature could be reached and where the flame should be oxidizing and then bringing it down by steps, nearer the burner, below the zone of maximum temperature, where the flame should be more reducing, under the following conditions.

Two burners, with converging flames were used, a steady blast from a blowing engine, the flame surrounded by perforated clay crucibles, the blast adjusted in each case so as to give the maximum heat, in the particular position; duration of each experiment thirty minutes.

Weight of the platinum crucible, II.9694 grams.

The following results were obtained: 
TABLE, B.

\begin{tabular}{|c|c|c|c|}
\hline $\begin{array}{c}\text { No. } \\
\text { of } \\
\text { Exp. }\end{array}$ & $\begin{array}{c}\text { Distance between } \\
\text { bottom of crucible } \\
\text { and the burners. } \\
\text { cm. }\end{array}$ & $\begin{array}{l}\text { Loss of } \\
\text { weight. } \\
\text { iggs. }\end{array}$ & $\begin{array}{l}\text { Loss pet is } \\
\text { ninutes. } \\
\text { Nyss. }\end{array}$ \\
\hline I. & I 5.5 & 2.0 & $\mathrm{I}$ \\
\hline 2. & 12.5 & I.I & 0.55 \\
\hline 3. & 10.5 & 0.8 & 0.40 \\
\hline 4. & 3.5 & 0.5 & 0.25 \\
\hline 5. & 7.5 & 0.5 & 0.25 \\
\hline 6. & 6.5 & 0.5 & 0.25 \\
\hline
\end{tabular}

Remarks.

Heat below that of four succeeding experiments.

Good white beat. f Heat higher that $\{$ in No. 2.

$\{$ Heat as high as in No. 3 .

Heat lower than in No. 5. Seemed about the same as in No. I.

In these experiments the loss in weight varied so much more with the position in the flame, than with the temperature, that the latter relation is entirely masked.

In all cases, where the wires lost weight, when heated by electricity in air or oxygen, mirrors were produced on the glass tube.

In Experiment No. 12, table A, the deposit was removed by aqua regia; only part of it dissolved at first in concentrated aqua regia, just as Nahrwold observed. The solution was filtered from the insoluble part, precipitated by ammonium chlorice, and the precipitate ignited. The residue weighed $56.3 \mathrm{milli}$ grams. The insoluble portion was ignited and found to weigh 56.4 milligrams. After ignition this residue dissolved in concentrated aqua regia. A further black precipitate was obtained from the alcoholic filtrate from the precipitation of the first aqua regia solution, which weighed 1.3 milligrams. Hence, if it is assumed that the mirror and these three fractions had about the same composition there were recovered in all I 4 milligrams out of 130.3 milligrams. Some of the deposit lay on the platinum supports and could not be recovered.

The behavior of the aqua regia solutions was very different from that of 30 milligrams of the original wire.

These experiments show that the loss of weight of commercial platinum heated by the electric current or before the blast-lamp, is due to the chemical action of oxygen, that certain elements are fractioned out of the impure platinum and that the loss of weight is not, as has been suspected, due to the use of "water- 
gas", except in so far as this gas is likely to give a hot and strongly oxidizing flame, when used in burners having an air supply, designed for a gas requiring more oxygen.

The behavior of platinum when heated under the last five conditions may be explained by the hypothesis that a volatile oxide of platinum is formed, stable at high and low temperatures, but unstable at intermediate temperatures, like the platinous chloride ( $\mathrm{Pt} \mathrm{Cl}_{2}$ ) of Troost and Hautefeuille.

If, as is the case in the blast-flame, the compound is swept away or if, as in the porcelain furnace in the combustion tube and with the heated wire, there is no cooler part of the platinum, upon which the metallic product of the decomposition of the hypothetical oxide can settle, the platinum loses weight. If on the contrary the flame is a quiet one, as is the case when a crucible is heated in a Bunsen flame, and only a part of the metal is very strongly heated, the hypothetical oxide decomposes at once on emerging from the most strongly heated zone and the platinum is deposited on the cooler part of the crucible, producing the molecular change of the surface, without gain or loss of weight, noticed by Erdmann and Crookes.

It is hoped to continue this work in this laboratory, to examine the deposit, to test the behavior of purer platinum, to try to isolate the hypothetical oxide and to fix, if possible, the conditions under which commercial platinum may be heated to whiteness without loss.

LABORATORY OF ANALYTICAL CHEMISTRY,

HAVEMEYER CHEMICAL LABORATORY,

NEW YORK UNIVERSITY, June, Igoo.

THE PRECIPITATION OF THE SULPHIDES OF NICKEL AND COBALT IN AN ALKALINE TARTRATE SOLUTION, TOGETHER WITH AN INVESTIGATION INTO THE NATURE OF CERTAIN TARTRATES OF THESE METALS.

BY O. F. TOWER. Received June I9, 1900

INTRODUCTION.

VILLIERS ${ }^{2}$ recommended some time ago a method for the qualitative separation of nickel and cobalt based on the action of hydrogen sulphide on an alkaline solution of the tartrates

1 Compt. rend. 84, 946 ( 1877$)$,

2 Ibid., IIg, I263, and $120,46(1894-95)$. 